\title{
Electrospun carbon nanofiber networks from phenolic resin for capacitive deionization
}

\author{
Yingzhi Chen ${ }^{\mathrm{a}}$, Mengbin Yue ${ }^{\mathrm{b}}$, Zheng-Hong Huang ${ }^{\mathrm{a},{ }^{*}}$, Feiyu Kang ${ }^{\mathrm{a}}$ \\ ${ }^{a}$ Key Laboratory of Advanced Materials (MOE), School of Materials Science and \\ Engineering, Tsinghua University, Beijing 100084, PR China \\ ${ }^{\mathrm{b}}$ School of Chemical and Environmental Engineering, China University of Mining and \\ Technology, Beijing 100083, PR China
}

\section{ABSTRACT}

The performance of capacitive deionization (CDI) mainly relies on the ion electrosorption capability. Here, we introduce a kind of free-standing, highly porous carbon nanofiber (CNF) networks with enhanced desalination capacity. The CNF networks were easily prepared by electrospinning of phenolic resin $(\mathrm{PhR})$ precursor followed by one-step carbonization step. The as-obtained PhR-based CNF networks exhibited characteristics of high flexibility, conductivity and specific surface area (SSA) along with favorable porosity, and hence demonstrated enhanced desalination capacity. When used as CDI electrodes, the PhR-based CNF networks have demonstrated a desalination capacity of $50.1 \mathrm{mg} \mathrm{g}^{-1}$ toward $2000 \mathrm{mg} \mathrm{L}^{-1}$ brackish water at $1.2 \mathrm{~V}$, much better than most reported data thus far. More importantly, easy recovery and good reproducibility could be obtained for such electrodes. Therefore, construction of PhR-based CNF network electrodes offers remarkable opportunities for

*Corresponding author. Tel: +86106277 3752. Fax: +861062771160.

E-mail address: zhhuang@ @ail.tsinghua.edu.cn (Z.-H. Huang). 
improving CDI capabilities and reliability given its simplicity, easy operation, and high performance.

Keywords:

Electrospinning

Carbon nanofiber

Capacitive deionization

\section{Introduction}

Fresh water scarcity constitutes an increasing concern on the earth, and demands a satisfactory solution to increase its availability[1,2]. Unfortunately, most of the established desalination technologies such as thermal processes, electrodialysis (ED), and reverse osmosis (RO), require specialized and expensive infrastructure. By contrast, capacitive deionization (CDI) represents a novel and energy-efficient desalination method, considering that it is an electrochemical water treatment technique that promotes the adsorption of ions in the electrochemical double layer (EDL) of a charged electrode surface, thus storing energy in the form of a capacitor and producing deionized water[3-6]. Detailed comparisons of various desalination technologies are provided in Table 1. The greatest advantage of CDI is its high theoretical energy efficiency for desalination. For instance, energy consumption of CDI is 
less than $0.6 \mathrm{kWh} \cdot \mathrm{m}^{-3}$ for total dissolved solids (TDS) removal from brackish water, much lower than that of other desalination techniques like RO $\left(2.9-3.7 \mathrm{kWh} \cdot \mathrm{m}^{-3}\right)$, thermal processes $\left(\right.$ over $\left.4 \mathrm{kWh} \cdot \mathrm{m}^{-3}\right)$ and $\mathrm{ED}\left(2.64-5.5 \mathrm{kWh} \cdot \mathrm{m}^{-3}\right)[2,7-11]$. Another noteworthy advantage is its low equipment and operational costs because CDI is a low-pressure, non-membrane based desalination process that is controlled by a low applied voltage. These capabilities render CDI increasingly applicable in desalination. For CDI technique, the high performance usually depends on the physical and structural properties of the electrode materials such as surface area, conductivity, porosity and mechanical strength. Among the electrode materials available for CDI, porous carbon materials form the major part, including carbon aerogels[5, 12-14], activated carbon clothes[15-17], ordered mesoporous carbons[18-20], carbon nanotubes (CNT)[21, 22], graphene sheets[23, 24] or different composites[25-32]. However, their fabrication either introduces some conductivity or porosity loss due to additives (like conductive agent or polymer binder), or suffers from high cost. Therefore, an easily prepared, free-standing carbon material with favourable porosity and flexibility is considered to be an ideal candidate to approach high-performance and long life-time CDI device.

\section{Table 1}


Comparison of desalination technologies.

\begin{tabular}{|c|c|c|c|c|}
\hline $\begin{array}{l}\text { Desalination } \\
\text { Technology }\end{array}$ & Thermal & ED & RO & CDI \\
\hline $\begin{array}{c}\text { Basic } \\
\text { Mechanism }\end{array}$ & $\begin{array}{l}\text { Steam is salt-free, } \\
\text { condenses to form } \\
\text { pure water. }\end{array}$ & $\begin{array}{l}\text { lons move through } \\
\text { anions \& cation } \\
\text { membrane }\end{array}$ & $\begin{array}{l}\text { Pressure>osmotic pressure, } \\
\text { water through polymer film, } \\
\text { salts retained }\end{array}$ & $\begin{array}{l}\text { lons adsorb and / desorb } \\
\text { on electrode due to DC } \\
\text { voltage }\end{array}$ \\
\hline Feed Water & Sea water & Brackish water only & Sea water \& Brackish water & Brackish water only \\
\hline $\begin{array}{c}\text { Energy } \\
\text { Requirement }\end{array}$ & $\begin{array}{c}\text { Thermal \& Electrical, } \\
\qquad>4 \mathrm{kWh} \cdot \mathrm{m}^{-3}\end{array}$ & $\begin{array}{c}\text { Electrical, } \\
2.64-5.5 \mathrm{kWh} \cdot \mathrm{m}^{-3}\end{array}$ & $\begin{array}{c}\text { Electrical, } \\
\text { 2.9-3.7 } \mathrm{kWh} \cdot \mathrm{m}^{-3}\end{array}$ & $\begin{array}{l}\text { Electrical, } \\
<0.6 \mathrm{kWh} \cdot \mathrm{m}^{-3}\end{array}$ \\
\hline $\begin{array}{c}\text { Total Capital } \\
\text { Cost }\end{array}$ & High & Medium-high & Low & Low \\
\hline Status & Major application & $\begin{array}{l}\text { Significant for low } \\
\text { salt feeds }\end{array}$ & Major application & Developmental \\
\hline Strengths & Well established & Well established & $\begin{array}{c}\text { Established, } \\
\text { Lower energy demand }\end{array}$ & $\begin{array}{c}\text { Removes minor ions, } \\
\text { Energy recovery }\end{array}$ \\
\hline Weakness & Energy demand & $\begin{array}{c}\text { Sea water } \\
\text { desalination is a } \\
\text { topic. }\end{array}$ & Energetic efficiency is low. & $\begin{array}{c}\text { Sea water desalination is } \\
\text { difficult. }\end{array}$ \\
\hline Breakthrough & Negligible & Negligible & Possible & Possible \\
\hline $\begin{array}{l}\text { Challenge } \\
\text { Analysis }\end{array}$ & $\begin{array}{l}\text { Better scale control, } \\
\text { materials, hybrid } \\
\text { optimization }\end{array}$ & $\begin{array}{l}\text { Lower cost, } \\
\text { membranes \& ED } \\
\text { optimization }\end{array}$ & $\begin{array}{l}\text { Better membranes and } \\
\text { module design; High } \\
\text { performance membrane from } \\
\text { nanotechnology; }\end{array}$ & $\begin{array}{l}\text { Practical modules and } \\
\text { scale-up; Novel } \\
\text { nano-structures electrodes } \\
\text { with high energy recovery. }\end{array}$ \\
\hline
\end{tabular}

Brackish water TDS: 800-3200 mg/L, Sea water TDS: 35000 mg/L

Recently, tremendous attentions have been paid to electrospun carbon nanofiber (CNF) networks[33, 34], because their high electrical conductivity, high specific surface area (SSA), and free-standing nature have made them extensively employed in applications such as capacitor[35-37], adsorbent[38, 39], and catalyst support[40]. Given these unique properties, electrospun $\mathrm{CNF}$ networks pose a great potential in realizing high-performance CDI. Preliminary works have been demonstrated by using electrospun activated carbon nanofiber (ACNF) networks from polyacrylonitrile (PAN) precursor for CDI[41, 42]. However, an additional activation treatment is always necessary to create the high porosity, which not only complicates the assembly, but also brings about some carbon yield loss or flexibility 
impairment. Thus, development of electrospun porous CNF networks in one-step carbonization is still of great importance for progressing CDI devices.

In this context, we demonstrate the first example of using phenolic resin-based carbon nanofiber (PhR CNF) networks for CDI. Among various carbon precursors, the major advantage of $\mathrm{PhR}$ is associated with its high carbon yield, dimensional stability, low cost, and high microporosity produced during the carbonization[43-45]. Herein, taking advantage of PhR, CNF networks with favorable pore size and high Brunauer-Emmett-Teller (BET) SSA, were easily prepared through electrospinning followed by one-step carbonization. Consequently, high ion removal is achieved for the resulted PhR CNF network electrode at a low voltage of $1.2 \mathrm{~V}$. Furthermore, easy recovery and good recycling could be attainable for CDI by such electrode. In view of simplicity, high adsorption capacity, and stability, organization of $\mathrm{PhR} \mathrm{CNF}$ networks provides an exciting alternative for achieving high-performance CDI.

\section{Experimental}

\subsection{Materials and preparation}

The precursor $\mathrm{PhR}$ (resol, $\mathrm{M}_{\mathrm{w}}=2,080$ ) was purchased from Durez Corporation, USA. Poly(vinyl butyral) (PVB, $\mathrm{M}_{\mathrm{w}}=303,800$ ) was purchased from Chemical Reagent Beijing Co., Ltd. In a typical experiment as we previously reported[45], the $\mathrm{PhR}(25 \mathrm{wt} \%)$ and $\mathrm{PVB}(0.6$ $\mathrm{wt} \%$ ) were dissolved in ethanol to form the polymer solution. Addition of PVB was to adjust the viscosity of the solution. Electrospinning of the polymer solution was conducted with a spinning distance of about $25 \mathrm{~cm}$, a flow rate of $1 \mathrm{ml} / \mathrm{h}$, and an applied voltage of $25 \mathrm{kV}$ to 
obtain the polymer fibers. The as-spun fibers were then cured at a stepwise heating until 180 ${ }^{\circ} \mathrm{C}$ for $1 \mathrm{~h}$, followed by carbonization for $1 \mathrm{~h}$ under a continuous nitrogen purge at 600,800 , or $1000{ }^{\circ} \mathrm{C}$. The resulted PhR CNFs were denoted as CNF-600, CNF-800, or CNF-1000, accordingly. For three samples, the carbonization yield is all higher than $50 \mathrm{wt} \%$, and relatively high compared with carbon fibers produced from other precursors. Here, the three carbonization temperature is chosen by reference to our previous work[45], considering that carbonizing at even higher temperature would otherwise cause a quite small SSA.

\subsection{Characterizations}

The scanning electron microscopic measurements were carried out using scanning electron microscope (SEM, LEO-1530, Germany), operated at an accelerating voltage of $10 \mathrm{kV}$. Porous structure was investigated from $\mathrm{N}_{2}$ adsorption at $77 \mathrm{~K}$ (Quantachrome Autosorb-1, USA). Samples were degassed at $195{ }^{\circ} \mathrm{C}$ for $18 \mathrm{~h}$ before test. The electrical resistivity was measure four times with a four-probe method at room temperature, of which the values were averaged. Surface chemistry composition of three samples was characterized by X-ray photoelectron spectroscopy (XPS, ESCALAB250Xi, ThermoFisher). The electrochemical measurements of individual electrode were carried out in a three-electrode cell, in which platinum wire and saturated calomel electrode (SCE) were employed as counter and reference electrodes, respectively. The cyclic voltammetry (CV), and electrochemical impedance spectra (EIS) were performed on $\mathrm{CHI}$ 660B electrochemical workstation in a $1 \mathrm{M} \mathrm{NaCl}$ electrolyte. The specific capacitance was calculated according to eq. (1):

$$
C=\int \frac{i d V}{2 v \Delta V m}
$$


Where $\mathrm{C}$ is the specific capacitance $(\mathrm{F} / \mathrm{g}), \mathrm{i}$ is the response current density $(\mathrm{A}), \Delta \mathrm{V}$ is the potential window $(\mathrm{V}), \mathrm{v}$ is the potential scan rate $(\mathrm{V} / \mathrm{s})$ and $\mathrm{m}$ is the mass of electrode material $(\mathrm{g})$.

\subsection{CDI capacity measurement}

The flexible PhR CNF networks used as CDI electrodes can be directly pressed onto the graphite current collector without any additives. A typical configuration of the flow-through CDI cell usually comprises two juxtaposed electrodes with an insulating spacer sandwiched between them, just as depicted in Fig. 1. Each CNF network electrode was tailored into an area of $3 \times 3 \mathrm{~cm}^{2}$, and its CDI capacity for ions was tested. Briefly, a $\mathrm{NaCl}$ aqueous solution was continuously pumped into CDI cell at a rate of $6 \mathrm{~mL} / \mathrm{min}$ from a peristaltic pump. The solution temperature was kept at $25^{\circ} \mathrm{C}$, and a constant voltage of $1.2 \mathrm{~V}$ was applied between the two electrodes. The change of $\mathrm{NaCl}$ concentration in the solution was continuously monitored using an ion conductivity meter (type 308 A, Leici Company). The CDI capacity was calculated according to eq. (2):

$$
\Gamma=\frac{\left(C_{0}-C\right) V}{M}
$$

Where $\Gamma$ is the CDI capacity or the amount of electrosorbed $\mathrm{NaCl}\left(\mathrm{mg} \mathrm{g}^{-1}\right), \mathrm{C}_{0}$ is the initial concentration $\left(\mathrm{mg} \mathrm{L}^{-1}\right), \mathrm{C}$ is the final molar concentration $\left(\mathrm{mg} \mathrm{L}^{-1}\right), \mathrm{V}$ is the volume of $\mathrm{NaCl}$ solution (L), M is the total mass of two electrodes (g). 


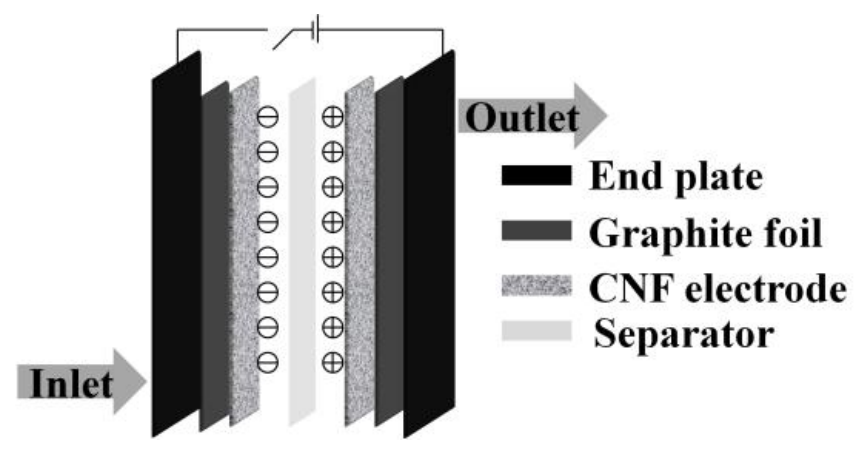

Fig. 1. Schematic illustration of a flow-through CDI set-up.

\subsection{Charge efficiency evaluation}

During CDI process, the charge efficiency was calculated as the ratio of the amount of electrosorbed ions over the equivalent total charge that given by eq. (3):

$$
\Lambda=\frac{\Gamma \times F}{\Sigma}
$$

Where $\mathrm{F}$ is Faraday constant $(96485 \mathrm{C} / \mathrm{mol}), \Gamma$ is referred to eq. (2) and $\Sigma$ can be obtained by integrating the current over time that given by eq. (4):

$$
\Sigma=\frac{\int i d t}{M}
$$

Where $\mathrm{i}$ is the current (A), $\mathrm{M}$ is the total mass of two electrodes (g).

\section{Results and discussion}

Fig. 2 shows the optical and SEM images of three kinds of carbonized samples treated under different temperatures. The as-obtained object features a paper-like and robust structure, and is bent to demonstrate its strength and flexibility (see CNF-1000 as an example in Fig. 2A-2B). Fig. 2C-2E show the SEM images and fiber diameter distributions of CNF-600, CNF-800 and CNF-1000. It can be found that all three samples have a fiber-like shape and stack randomly to form a network structure. Note that the average fiber diameter was 
decreased gradually when the carbonization temperature increased (see details in Table 2).

The average diameter of the thinnest carbonized fibers was $810 \mathrm{~nm}$ for CNF-1000.

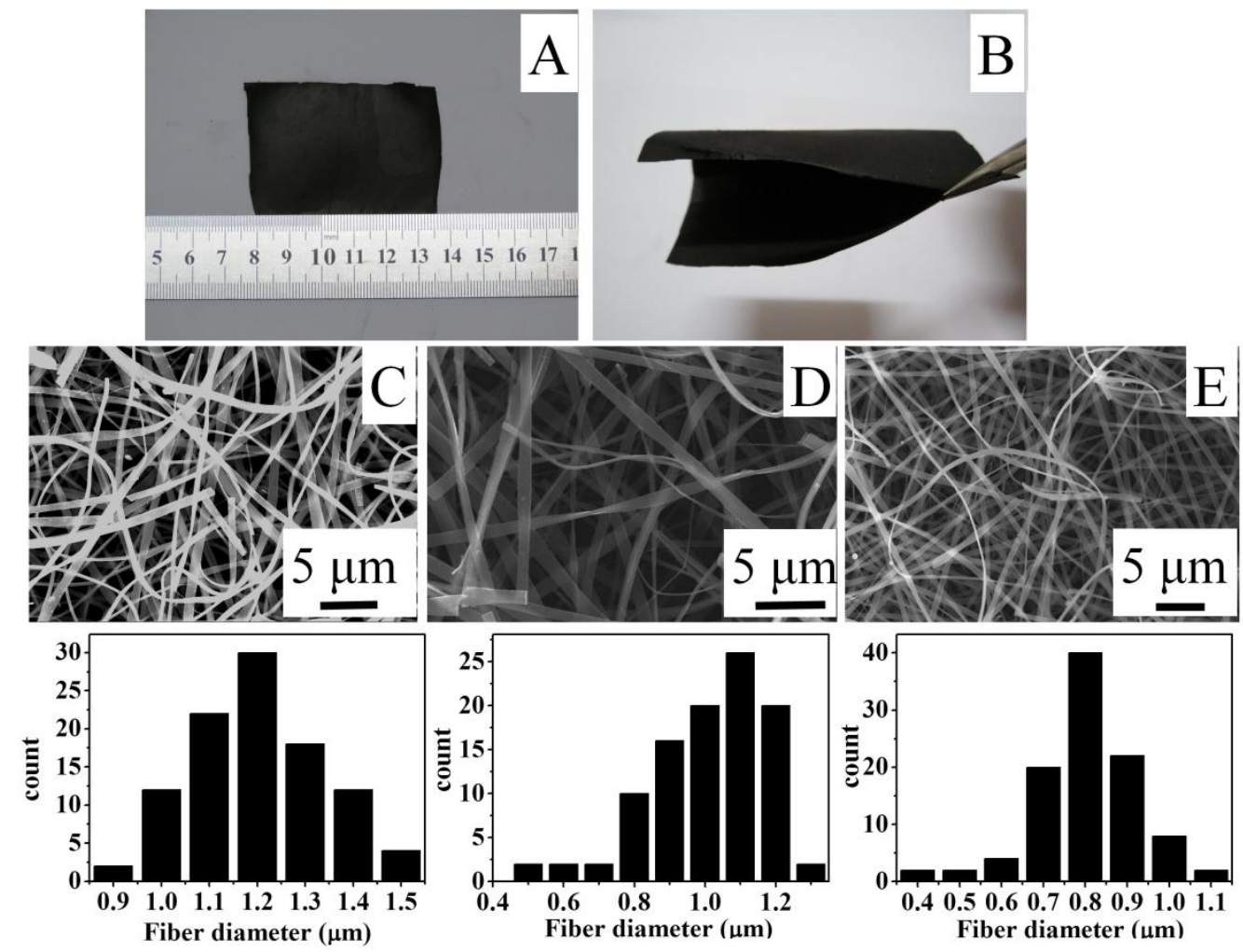

Fig. 2. The optical images of CNF-1000 (A, B) and SEM images of CNF-600 (C), CNF-800 (D), and CNF-1000 (E), and their corresponding fiber diameter distributions.

It has also been found that the electrical conductivity of $\mathrm{PhR}$ CNF networks can be significantly improved by increasing the carbonization temperature. CNF-600 demonstrates the highest electrical resistivity of about $52.95 \Omega \mathrm{cm}$. The resistivity measured for CNF-800 is $10.53 \Omega \mathrm{cm}$ on average, while for CNF-1000, it is only $2.76 \Omega \mathrm{cm}$. The apparent reduction in the resistivity of CNF-1000 is probably associated with the reduced oxy-surface-groups brought by the higher thermal treatment. To better understand the surface chemistry change, XPS analysis was employed to deconvolve the C 1s spectra of the three PhR CNF networks. As shown in Fig. 3, the C 1s spectra were deconvolved into three peaks centred at 284.7, 
286.1, and $288.8 \mathrm{eV}$ which could be assigned to $\mathrm{C}=\mathrm{C}$ (graphitized carbon), $\mathrm{C}-\mathrm{O}$ (carbon in alcohol or ether groups) and $\mathrm{O}-\mathrm{C}=\mathrm{O}$ (carbon in carboxyl or ester groups), respectively. Table 2 revealed that with increasing the carbonization temperature, the relative content of graphitized carbon increased and that of oxy-surface-groups decreased. Because of this, the electrical conductivity of CNF-1000 gains a great enhancement compared to CNF-800 and CNF-600. Expectedly, the enhanced conductivity will be quite beneficial for the EDL formation for charge holding that finally renders a high-performance CDI.

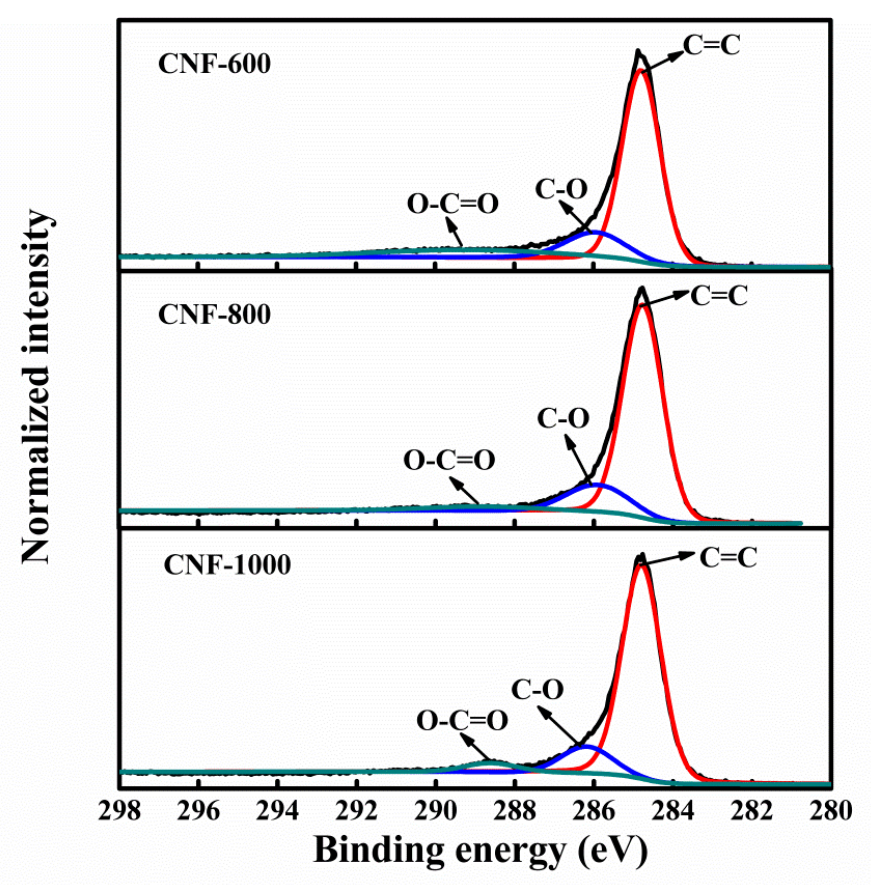

Fig. 3. XPS spectra of $\mathrm{C} 1 \mathrm{~s}$ region of the obtained three PhR CNF networks.

Fig. 4A shows the $\mathrm{N}_{2}$ adsorption-desorption isotherms for three PhR CNF networks. According to the IUPAC classification, all three samples exhibit a typical type I isotherm, suggesting the main presence of micropores in the porous structure. It is noteworthy that pores can be classified as macropores (pore diameter $>50 \mathrm{~nm})$, mesopores $(2-50 \mathrm{~nm})$, and micropores $(<2 \mathrm{~nm})$. Detailed porous characteristics of the obtained PhR CNF networks are 
listed in Table 2. It can be seen that a progressive increase in BET SSA is attainable as carbonization temperature is raised from 600 to $1000{ }^{\circ} \mathrm{C}$. Of them, $\mathrm{CNF}-1000$ showed the highest SSA area up to $617 \mathrm{~m}^{2} \mathrm{~g}^{-1}$. The increase of SSA is caused by the increased porosity of PhR CNF networks and the decrease in the fiber diameter. The pore size distribution in different CNF networks was estimated by the density function theory (DFT, Fig. 4B). As it showed, the pore size peaks for three CNF networks were mainly found below $2 \mathrm{~nm}$. Increasing studies have demonstrated that micropores might contribute more substantially to CDI desalination capacity than larger pores[46, 47].
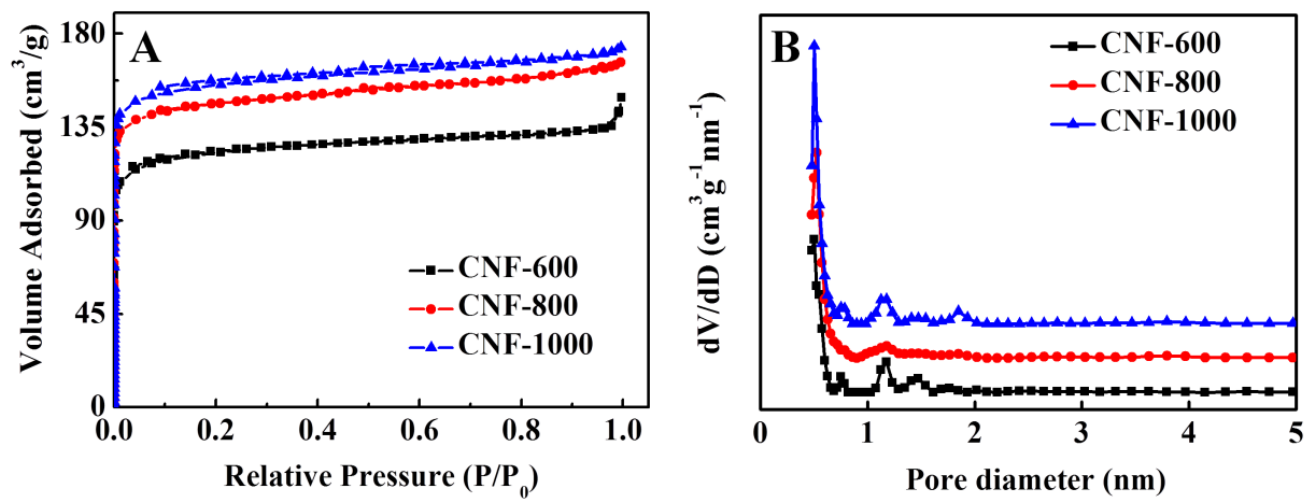

Fig. 4. (A) Nitrogen adsorption-desorption isotherms and (B) pore size distributions of the three PhR CNF networks.

\section{Table 2}

Physicochemical and electrochemical properties of PhR CNF networks.

\begin{tabular}{|c|c|c|c|c|c|c|c|c|c|c|}
\hline \multirow{2}{*}{ Sample } & \multirow{2}{*}{$\begin{array}{c}\text { Fiber } \\
\text { diameter }(\mu \mathrm{m})\end{array}$} & \multirow{2}{*}{$\begin{array}{c}\text { Electrical } \\
\text { resistivity }(\Omega \mathrm{cm})\end{array}$} & \multirow{2}{*}{$\begin{array}{l}\mathrm{C}=\mathrm{C}^{\mathrm{a}} \\
\text { (at.\%) }\end{array}$} & \multirow{2}{*}{$\begin{array}{l}\text { C-O } \\
\text { (at.\%) }\end{array}$} & \multirow{2}{*}{$\begin{array}{l}\mathrm{O}-\mathrm{C}=\mathrm{O}^{\mathrm{a}} \\
\text { (at.\%) }\end{array}$} & \multirow{2}{*}{$\begin{array}{l}\text { SSA } \\
\left(\mathrm{m}^{2} \mathrm{~g}^{-1}\right)\end{array}$} & \multirow{2}{*}{$\begin{array}{c}V_{\text {total }} \\
\left(\mathrm{cm}^{3} \mathrm{~g}^{-1}\right)\end{array}$} & \multicolumn{3}{|c|}{ Specific Capacitance ${ }^{\mathrm{b}}(\mathrm{F} / \mathrm{g})$} \\
\hline & & & & & & & & $10 \mathrm{mV} / \mathrm{s}$ & $20 \mathrm{mV} / \mathrm{s}$ & $50 \mathrm{mV} / \mathrm{s}$ \\
\hline CNF-600 & 1.2 & 52.95 & 69.8 & 16.6 & 13.6 & 481 & 0.23 & 1.6 & 1.1 & 0.7 \\
\hline CNF-800 & 1.01 & 10.53 & 80.6 & 15.4 & 4 & 579 & 0.26 & 41.8 & 37.7 & 30.5 \\
\hline CNF-1000 & 0.81 & 2.76 & 83.2 & 12.5 & 4.3 & 617 & 0.27 & 52.1 & 48.8 & 41.4 \\
\hline
\end{tabular}


CV measurements of the obtained three PhR CNF electrodes were then conducted to evaluate their electrochemical properties, because specific capacitance in $\mathrm{NaCl}$ solution is an important factor for evaluating ions adsorption capacity[32]. Here, CV curves of the three $\mathrm{PhR}$ CNF electrodes were measured at a sweep rate of $10 \mathrm{mV} / \mathrm{s}$ in $1 \mathrm{M} \mathrm{NaCl}$ solution with the potential ranging from 0 to $0.9 \mathrm{~V}$ (Fig. $5 \mathrm{~A}$ ). The $\mathrm{CV}$ curve of CNF-1000 was found to be more rectangular in shape within the selected potential range than that of the other two, demonstrating its ideal EDL capacitor behavior. The calculation of specific capacitance based on the integrated area of CV curve shows that CNF-1000 has a high specific capacitance of $52.1 \mathrm{~F} / \mathrm{g}$, larger than that of CNF-800 (41.8 F/g) and CNF-600 (only $1.6 \mathrm{~F} / \mathrm{g}$ ). Table 2 summarizes the specific capacitance of three PhR CNF electrodes in $1 \mathrm{M} \mathrm{NaCl}$ solutions at different sweep rate. It can be seen that, among the three targeted electrodes, CNF-1000 exhibits the highest specific capacitance regardless of the sweep rate. This is caused by the increase in the effective SSA, pore volume and electrical conductivity.

The EIS analysis, representing as Nyquist plots, was performed to take a deep insight into the resistive and capacitive characteristics of the PhR CNF electrodes[48]. Fig. 5B presents the EIS of the three PhR CNF electrodes in $1 \mathrm{M} \mathrm{NaCl}$ solutions and inset shows the corresponding equivalent circuit. It can be clearly seen that all three $\mathrm{PhR} C \mathrm{CNF}$ electrodes exhibit the characteristic shape associated with a supercapacitor behavior; a semicircle at high frequency (namely polarization resistance $R_{p}$ ) relating to contact resistances and affected basically by the quality of cell assembly, uncompensated solution resistance $\mathrm{R}_{\mathrm{s}}$ from the first intercept point of $\mathrm{Z}^{\prime}$ axis of EIS which is corresponding to electrolyte conductivity, and a diffusion controlled process at low frequency (Warburg Impedance). As can be deduced from 
this figure, solution resistance was found to be $27.9,9.1$, and $4.1 \Omega$ for CNF-600, CNF-800, and CNF-1000, respectively. The polarization resistance represents the capacitive behavior at electrode-electrolyte interface, which indicates how much the double layer us polarized (accumulated ions). It is found this value changes slightly between CNF-1000 $(\sim 18.1 \Omega)$ and CNF-800 ( 18.4 $\Omega)$, but a great variation was observed in CNF-600 (536.1 $\Omega)$. Herein, the decreased resistance (either Rs or Rp) in CNF-1000 indicates that increasing conductivity by higher thermal treatment can lower the contact resistance between the electrode and the current collector or electrolyte. In view of the diffusion part, the Warburg impedance of CNF-1000 appears at relatively higher frequency than CNF-800 and CNF-600. The imaginary part of the impedance (-Z" axis) for CNF-1000 decreases slightly, implying CNF-1000 has a positive tendency for higher rate of diffusion, and the plot of CNF-1000 is more close to vertical line characteristic of a porous capacitor. These results show that CNF-1000 will be more advantageous in terms of energy consumption.
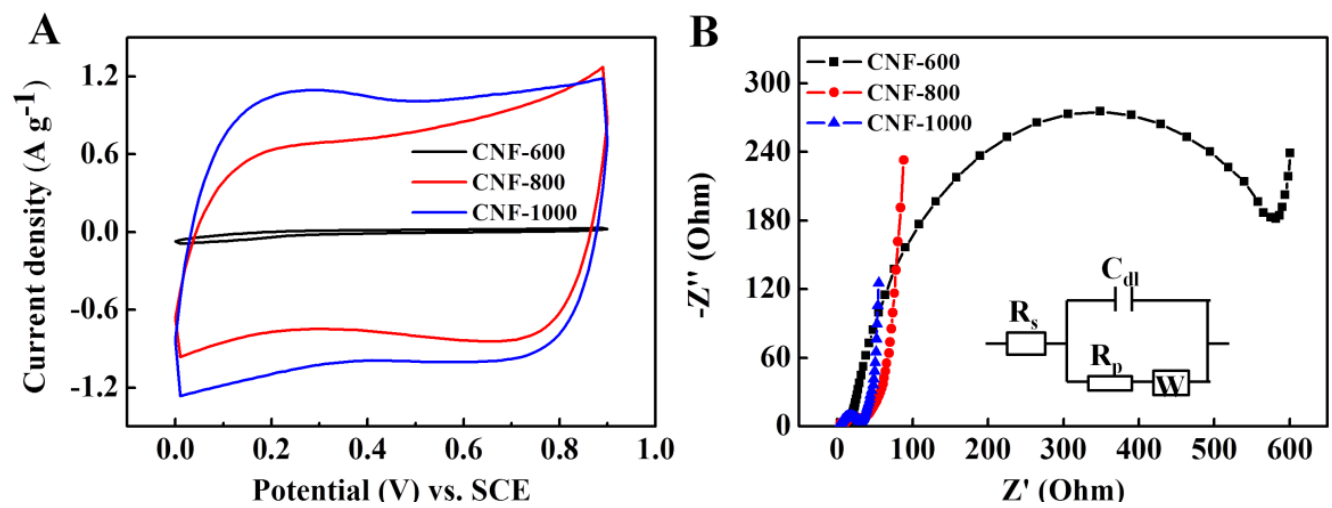

Fig. 5. (A) CV curves of the three PhR CNF electrodes at a sweep rate of $10 \mathrm{mV} / \mathrm{s}$ and (B) their EIS in $1 \mathrm{M} \mathrm{NaCl}$ solution. Inset in (B) is the corresponding equivalent circuit.

To investigate the feasibility of PhR CNF network electrodes in CDI unit, batch mode CDI experiments were conducted in $\mathrm{NaCl}$ solution with an initial conductivity around $170 \mu \mathrm{S} / \mathrm{cm}$ 
at an applied voltage of $1.2 \mathrm{~V}$. Fig. $6 \mathrm{~A}$ and $6 \mathrm{~B}$ show the electrosorption performance of three PhR CNF electrodes and their typical current response, respectively. It can be seen that the conductivity decreased gradually and reached minimum value after 1 hour, indicating the electrode became saturated. Accordingly, the current exhibits the same tendency. Based on eq. (2), the desalination capacity was calculated to be $2.0,6.3$, and $13.3 \mathrm{mg} \mathrm{g}^{-1}$ for CNF-600, CNF-800, and CNF-1000. The higher ion removing amount for CNF-1000 is consistent with its better supercapacitor behaviour. It is also known that the charge efficiency $\Lambda$ is a very functional tool to examine how much the electrical voltage contributes to the electrosorption[29, 49]. Theoretically, the charge efficiency is always less than 1 owing to the serious negative effect of co-ions. From Fig. 6B, together with eq. (4), the total charge during this CDI process is calculated to be 13.6, 36.8, and $63.3 \mathrm{C} / \mathrm{g}$ for CNF-600, CNF-800, and CNF-1000. Thus, it can be determined by eq. (3) that the charge efficiency of CNF-1000 is 0.35 at $1.2 \mathrm{~V}$, much higher than that of CNF-800 (0.28) and CNF-600 (0.26). The higher charge efficiency of CNF-1000 might be attributed to its higher conductivity and pore volume, and hence support well its better CDI performance. Table 3 summarizes the measured values for $\Lambda$ based on data for equilibrium charge $\Sigma$ and salt adsorption $\Gamma$ at a given applied voltage of $1.2 \mathrm{~V}$. It clearly points that a strong correlation exists between the capacitance of a material (how much charge can be stored for a given cell voltage, typically evaluated under conditions of use for EDL capacitors) and desalination performance in CDI. 

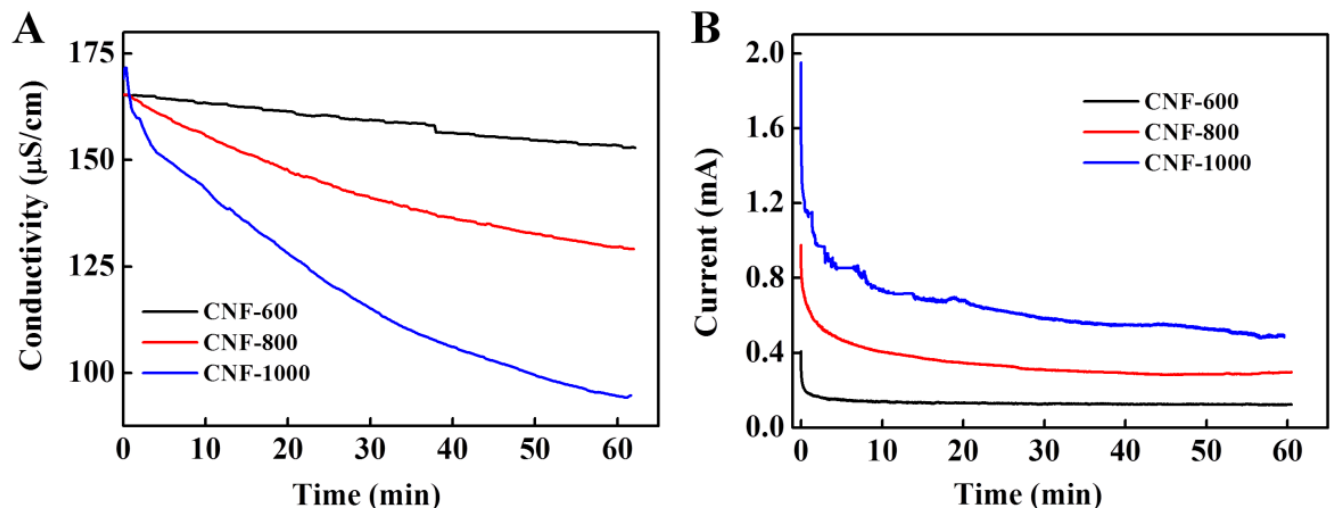

Fig. 6. The conductivity transient (A) and corresponding current response (B) for PhR CNF network electrodes in $\mathrm{NaCl}$ solution with an initial conductivity around $170 \mu \mathrm{S} \mathrm{cm}^{-1}$ at $1.2 \mathrm{~V}$.

\section{Table 3}

Salt electrosorption performance and charge efficiency for the three PhR CNF electrodes in $\mathrm{NaCl}$ solution with an initial conductivity around $170 \mu \mathrm{S} \mathrm{cm}-1$ at $1.2 \mathrm{~V}$.

\begin{tabular}{ccccc}
\hline Sample & Mass $(\mathrm{mg})$ & $\Gamma\left(\mathrm{mg} \mathrm{g}^{-1}\right)$ & $\Sigma(\mathrm{C} / \mathrm{g})$ & $\Lambda$ \\
\hline CNF-600 & 36 & 2 & 13.6 & 0.26 \\
CNF-800 & 34 & 6.3 & 36.8 & 0.28 \\
CNF-1000 & 36 & 13.3 & 63.3 & 0.35 \\
\hline
\end{tabular}

The effect of salt concentration on the CDI behaviors of the three PhR CNF electrodes is also examined in Table 4 for $\mathrm{NaCl}$ solutions with different initial concentrations ranging from 100 to $2000 \mathrm{ppm}$. It can be seen that the desalination capacity increases slowly with an increase in salt concentration for three electrodes, and CNF-1000 demonstrates the largest CDI capacity. Furthermore, CDI performance over different electrode materials are compared and summarized in Table 4. In detail, graphene-based (GR) electrodes usually exhibit high CDI capacity because of its better conductivity, but the chemically exfoliated GR electrode are often conducted at an applied voltage up to $1.6 \mathrm{~V}$ or $2 \mathrm{~V}[23,27,32]$; the relatively low SSA in CNT-based electrode sets a limitation on its CDI capacity[21, 50-52] ; mesoporous 
carbon[19, 20, 53, 54] is high in SSA, but increasing studies have shown the volume associated with micropores contributes more to total sorption capacity than mesopores which mainly facilitate ion transportation[47]. In comparison, the microporous CNF-1000 with its high conductivity and SSA can achieve enhanced CDI capacity at $1.2 \mathrm{~V}$, and its detailed desalination curves measured at different initial salt concentrations are presented in Fig. 7A. This very high value of CDI capacity here is in good agreement with the recent study on the importance of micropores[46, 47]. Additionally, the PhR CNF network electrode benefits much more from its monolithic structure than powder-like carbon materials that must be mixed with polymer binder. The involvement of the binder might occlude significant fractions of pores in reducing its total surface area and increasing the electrical and mass transport resistances. Moreover, one-step carbonization would produce considerable surface area in PhR CNF network compared with the activated PAN network used for CDI.

\section{Table 4}

Salt electrosorption performance reported for different electrode materials applied for CDI.

\begin{tabular}{|c|c|c|c|c|c|c|}
\hline Sample & $\begin{array}{l}\text { Applied } \\
\text { voltage } \\
\text { (V) }\end{array}$ & Category & $\begin{array}{c}\Gamma @ 100 \text { ppm }^{\mathrm{a}} \\
(\mathrm{mg} / \mathrm{g})\end{array}$ & $\begin{array}{c}\Gamma @ 500 \text { ppm }^{\mathrm{a}} \\
(\mathrm{mg} / \mathrm{g})\end{array}$ & $\begin{array}{c}\Gamma @ 800 \text { ppm }^{\mathrm{a}} \\
(\mathrm{mg} / \mathrm{g})\end{array}$ & $\begin{array}{c}\Gamma @ 2000 \mathrm{ppm}^{\mathrm{a}} \\
(\mathrm{mg} / \mathrm{g})\end{array}$ \\
\hline CNF-600 & 1.2 & flexible, monolithic & 4.3 & 13.2 & 15.7 & 20.1 \\
\hline CNF-800 & 1.2 & flexible, monolithic & 9.4 & 23.4 & 27.1 & 35.9 \\
\hline CNF-1000 & 1.2 & flexible, monolithic & 14.3 & 34.5 & 42.3 & 50.1 \\
\hline Ref [23] & 2 & suspension coated & - & - & & $\sim 21$ \\
\hline Ref [27] & 1.6 & bulky, fragile & - & - & & $\sim 70$ \\
\hline Ref [32] & 1.2 & suspension coated & - & 15.1 & & $\sim 20$ \\
\hline Ref [21] & 1.2 & flexible, monolithic & - & - & $<18$ & $\sim 30$ \\
\hline $\operatorname{Ref}[50]$ & 1.2 & binder added & - & - & & $<9.4$ \\
\hline $\operatorname{Ref}[51]$ & 1.2 & monolithic & $\sim 3.32$ & & & \\
\hline Ref [52] & 1.2 & monolithic & & $\sim 16$ & & \\
\hline Ref [53] & 1.2 & binder added & - & & $<6.1$ & $<14.6$ \\
\hline
\end{tabular}


Recycling tests were subsequently performed for the evaluation of CDI applicability. The initial conductivity of $\mathrm{NaCl}$ solution is $170 \mu \mathrm{S} \mathrm{cm}^{-1}$. When the conductivity returns to the initial value in the discharge process, the second charge starts. Fig. 7B shows the conductivity transient over 9 charge-discharge cycles on CNF-1000 network electrode. It was basically conducted by repeating charging $(1.2 \mathrm{~V})$ and discharging $(0 \mathrm{~V})$ for ionic adsorption and desorption. The figure clearly shows that the conductivity variation is finely reproducible for 9 cycles, confirming that our CNF-1000 network could be recycled well for successive CDI use. In the practical experiment, obvious decline in removal capacity has not been observed in our unit cell after 50 charge-discharge cycles. These results demonstrate that with this convenient PhR CNF-1000 network electrode, long life-time durability and reliability could be realized for CDI.

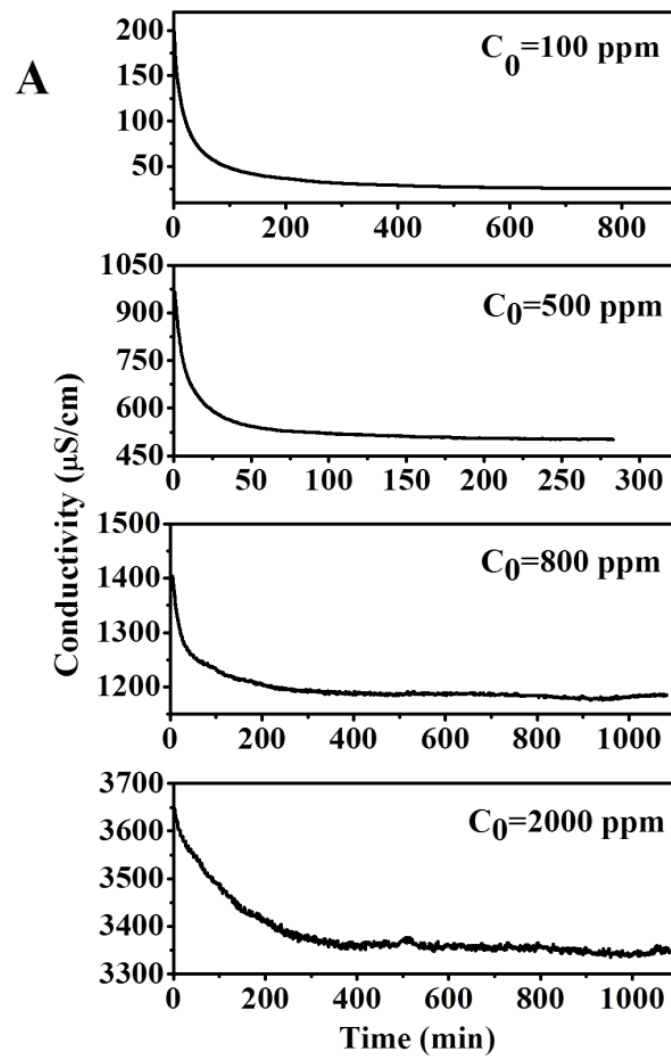

$\mathbf{B}$

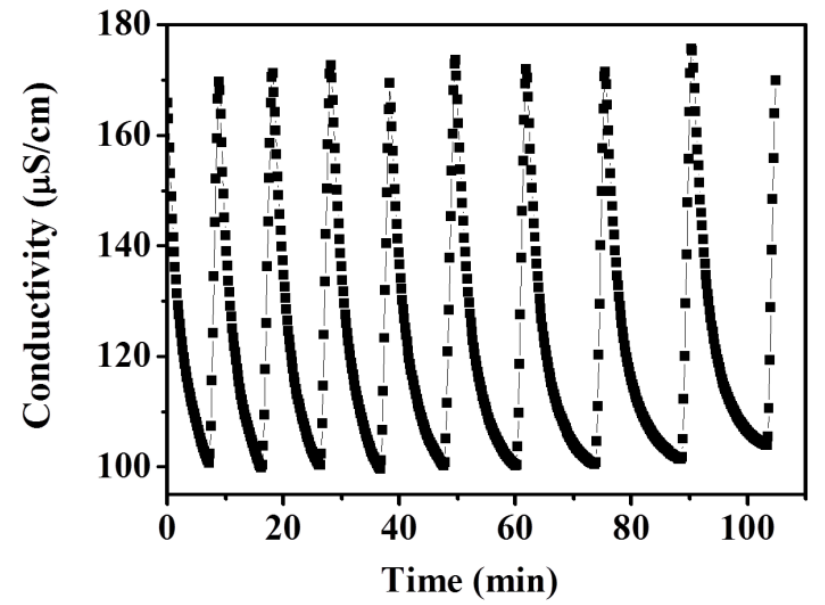

.Fig. 7. (A) Desalination curves measured on CNF-1000 in different initial concentrations of 
$\mathrm{NaCl}$ solutions; (B) The recycling of $\mathrm{CNF}-1000$ electrode in $\mathrm{NaCl}$ solutions with an initial conductivity of $170 \mu \mathrm{S} / \mathrm{cm}$. Total mass of CNF-1000 in two electrodes is $65 \mathrm{mg}$.

\section{Conclusions}

To conclude, we have developed electrospun PhR CNF network as a free-standing yet effective electrode-active material for high-performance, sustainable capacitive desalination. The PhR CNF network is simple in fabrication, cost-effective in operation, and free from complex treatment. One-step carbonization under appropriate temperature could introduce large surface area along with preferable microporosity accessible to ions. Thanks to it, a desalination capacity of $50.1 \mathrm{mg} \mathrm{g}^{-1}$ has been obtained toward $2000 \mathrm{mg} \mathrm{L}^{-1}$ brackish water, much better than the mostly reported data. Moreover, the as-fabricated electrode also displayed good reproducibility after several repeated runs. The advantages of PhR CNF network electrode presented here make it a promising candidate for practical CDI applications.

\section{Acknowledgements}

The authors are grateful for the financial support from the National Natural Science Foundation of China (Grant No. 51072091), the cooperative project JST-MOST (No. 2011DFA50430), and the Program for New Century Excellent Talents in University (NCET-10-0496).

\section{References}

[1] M.A. Shannon, P.W. Bohn, M. Elimelech, J.G. Georgiadis, B.J. Mariñas, A.M. Mayes, 
Science and technology for water purification in the coming decades, Nature 452 (2008) 301-310.

[2] S.J. Kim, S.H. Ko, K.H. Kang, J. Han, Direct seawater desalination by ion concentration polarization, Nat. Nanotechnol. 5 (2010) 297-301.

[3] P. Biesheuvel, B. Van Limpt, A. Van der Wal, Dynamic adsorption/desorption process model for capacitive deionization, J.Phys.Chem.C 113 (2009) 5636-5640.

[4] T. Humplik, J. Lee, S. O’Hern, B. Fellman, M. Baig, S. Hassan, M. Atieh, F. Rahman, T. Laoui, R. Karnik, Nanostructured materials for water desalination, Nanotechnology 22 (2011) 292001.

[5] K.-L. Yang, T.-Y. Ying, S. Yiacoumi, C. Tsouris, E.S. Vittoratos, Electrosorption of ions from aqueous solutions by carbon aerogel: An electrical double-layer model, Langmuir 17 (2001) 1961-1969.

[6] M. Noked, E. Avraham, A. Soffer, D. Aurbach, The rate-determining step of electroadsorption processes into nanoporous carbon electrodes related to water desalination, J.Phys.Chem.C 113 (2009) 21319-21327.

[7] M. Elimelech, W.A. Phillip, The future of seawater desalination: Energy, technology, and the environment, Science 333 (2011) 712-717.

[8] H.L. Yang, C. Huang, J.C.-T. Lin, Seasonal fouling on seawater desalination RO membrane, Desalination 250 (2010) 548-552.

[9] M. Turek, Cost effective electrodialytic seawater desalination, Desalination 153 (2003) $371-376$.

[10] H. Al-Fulaij, A. Cipollina, H. Ettouney, D. Bogle, Simulation of stability and dynamics 
of multistage flash desalination, Desalination 281 (2011) 404-412.

[11] M. Pasta, C.D. Wessells, Y. Cui, F. La Mantia, A Desalination Battery, Nano Lett. 12 (2012) 839-843.

[12] J.C. Farmer, D.V. Fix, G.V. Mack, R.W. Pekala, J.F. Poco, Capacitive deionization of $\mathrm{NaCl}$ and NaNO3 solutions with carbon aerogel electrodes, J. Electrochem. Soc. 143 (1996) 159-169.

[13] H.-H. Jung, S.-W. Hwang, S.-H. Hyun, K.-H. Lee, G.-T. Kim, Capacitive deionization characteristics of nanostructured carbon aerogel electrodes synthesized via ambient drying, Desalination 216 (2007) 377-385.

[14] J. Biener, M. Stadermann, M. Suss, M.A. Worsley, M.M. Biener, K.A. Rose, T.F. Baumann, Advanced carbon aerogels for energy applications, Energy Environ.Sci. 4 (2011) 656-667.

[15] A. Afkhami, Adsorption and electrosorption of nitrate and nitrite on high-area carbon cloth: an approach to purification of water and waste-water samples, Carbon 41 (2003) $1320-1322$.

[16] H.-J. Oh, J.-H. Lee, H.-J. Ahn, Y. Jeong, Y.-J. Kim, C.-S. Chi, Nanoporous activated carbon cloth for capacitive deionization of aqueous solution, Thin Solid Films 515 (2006) $220-225$.

[17] M.-W. Ryoo, J.-H. Kim, G. Seo, Role of titania incorporated on activated carbon cloth for capacitive deionization of $\mathrm{NaCl}$ solution, J. Colloid Interface Sci. 264 (2003) 414-419.

[18] X. Wang, J.S. Lee, C. Tsouris, D.W. DePaoli, S. Dai, Preparation of activated mesoporous carbons for electrosorption of ions from aqueous solutions, J. Mater. Chem. 20 
(2010) 4602-4608.

[19] L. Li, L. Zou, H. Song, G. Morris, Ordered mesoporous carbons synthesized by a modified sol-gel process for electrosorptive removal of sodium chloride, Carbon 47 (2009) 775-781.

[20] J.O. áKiggans Jr, Hierarchical ordered mesoporous carbon from phloroglucinol-glyoxal and its application in capacitive deionization of brackish water, J. Mater. Chem. 20 (2010) $8674-8678$.

[21] L. Wang, M. Wang, Z.-H. Huang, T. Cui, X. Gui, F. Kang, K. Wang, D. Wu, Capacitive deionization of $\mathrm{NaCl}$ solutions using carbon nanotube sponge electrodes, J. Mater. Chem. 21 (2011) 18295-18299.

[22] K. Dai, L. Shi, J. Fang, D. Zhang, B. Yu, NaCl adsorption in multi-walled carbon nanotubes, Mater. Lett. 59 (2005) 1989-1992.

[23] H. Li, T. Lu, L. Pan, Y. Zhang, Z. Sun, Electrosorption behavior of graphene in $\mathrm{NaCl}$ solutions, J. Mater. Chem. 19 (2009) 6773-6779.

[24] B. Jia, L. Zou, Graphene nanosheets reduced by a multi-step process as high-performance electrode material for capacitive deionisation, Carbon 50 (2012) $2315-2321$.

[25] D. Zhang, T. Yan, L. Shi, Z. Peng, X. Wen, J. Zhang, Enhanced capacitive deionization performance of graphene/carbon nanotube composites, J. Mater. Chem. 22 (2012) 14696-14704.

[26] Z. Wang, L. Yue, Z.-T. Liu, Z.-H. Liu, Z. Hao, Functional graphene nanocomposite as an electrode for the capacitive removal of $\mathrm{FeCl}_{3}$ from water, J. Mater. Chem. 22 (2012) 
14101-14107.

[27] Z. Sui, Q. Meng, X. Zhang, R. Ma, B. Cao, Green synthesis of carbon nanotube-graphene hybrid aerogels and their use as versatile agents for water purification, $\mathrm{J}$. Mater. Chem. 22 (2012) 8767-8771.

[28] Z. Peng, D. Zhang, L. Shi, T. Yan, High performance ordered mesoporous carbon/carbon nanotube composite electrodes for capacitive deionization, J. Mater. Chem. 22 (2012) 6603-6612.

[29] H. Li, S. Liang, J. Li, L. He, The capacitive deionization behaviour of a carbon nanotube and reduced graphene oxide composite, J. Mater. Chem. A 1 (2013) 6335-6341.

[30] H. Li, L. Pan, C. Nie, Y. Liu, Z. Sun, Reduced graphene oxide and activated carbon composites for capacitive deionization, J. Mater. Chem. 22 (2012) 15556-15561.

[31] X. Wang, M. Li, Y. Chen, R. Cheng, S. Huang, L. Pan, Z. Sun, Electrosorption of ions from aqueous solutions with carbon nanotubes and nanofibers composite film electrodes, Appl. Phys. Lett. 89 (2006) 053127-053127-053123.

[32] H. Yin, S. Zhao, J. Wan, H. Tang, L. Chang, L. He, H. Zhao, Y. Gao, Z. Tang, ThreeDimensional Graphene/Metal Oxide Nanoparticle Hybrids for High-Performance Capacitive Deionization of Saline Water, Adv.Mater. 25 (2013) 6270-6276.

[33] Z. Zhou, X.-F. Wu, H. Fong, Electrospun carbon nanofibers surface-grafted with vapor-grown carbon nanotubes as hierarchical electrodes for supercapacitors, Appl. Phys. Lett. 100 (2012) 023115-023115-023114.

[34] Z. Zhou, C. Lai, L. Zhang, Y. Qian, H. Hou, D.H. Reneker, H. Fong, Development of carbon nanofibers from aligned electrospun polyacrylonitrile nanofiber bundles and 
characterization of their microstructural, electrical, and mechanical properties, Polymer 50 (2009) 2999-3006.

[35] C. Kim, B.T.N. Ngoc, K.S. Yang, M. Kojima, Y.A. Kim, Y.J. Kim, M. Endo, S.C. Yang, Self-Sustained Thin Webs Consisting of Porous Carbon Nanofibers for Supercapacitors via the Electrospinning of Polyacrylonitrile Solutions Containing Zinc Chloride, Adv.Mater. 19 (2007) 2341-2346.

[36] E. Ra, E. Raymundo-Piñero, Y. Lee, F. Béguin, High power supercapacitors using polyacrylonitrile-based carbon nanofiber paper, Carbon 47 (2009) 2984-2992.

[37] C. Kim, K. Yang, Electrochemical properties of carbon nanofiber web as an electrode for supercapacitor prepared by electrospinning, Appl. Phys. Lett. 83 (2003) 1216-1218.

[38] K.J. Lee, N. Shiratori, G.H. Lee, J. Miyawaki, I. Mochida, S.-H. Yoon, J. Jang, Activated carbon nanofiber produced from electrospun polyacrylonitrile nanofiber as a highly efficient formaldehyde adsorbent, Carbon 48 (2010) 4248-4255.

[39] M. Teng, J. Qiao, F. Li, P.K. Bera, Electrospun mesoporous carbon nanofibers produced from phenolic resin and their use in the adsorption of large dye molecules, Carbon 50 (2012) $2877-2886$.

[40] S.H. Joo, S.J. Choi, I. Oh, J. Kwak, Z. Liu, O. Terasaki, R. Ryoo, Ordered nanoporous arrays of carbon supporting high dispersions of platinum nanoparticles, Nature 412 (2001) 169-172.

[41] G. Wang, C. Pan, L. Wang, Q. Dong, C. Yu, Z. Zhao, J. Qiu, Activated carbon nanofiber webs made by electrospinning for capacitive deionization, Electrochim. Acta 69 (2012) $65-70$. 
[42] G. Wang, Q. Dong, Z. Ling, C. Pan, C. Yu, J. Qiu, Hierarchical activated carbon nanofiber webs with tuned structure fabricated by electrospinning for capacitive deionization, J. Mater. Chem. 22 (2012) 21819-21823.

[43] K. Suzuki, H. Matsumoto, M. Minagawa, M. Kimura, A. Tanioka, Preparation of carbon fiber fabrics from phenolic resin by electrospray deposition, Polym. J. 39 (2007) 1128-1134.

[44] S. Imaizumi, H. Matsumoto, K. Suzuki, M. Minagawa, M. Kimura, A. Tanioka, Phenolic resin-based carbon thin fibers prepared by electrospinning: additive effects of poly (vinyl butyral) and electrolytes, Polym. J. 41 (2009) 1124-1128.

[45] L. Wang, Z.-H. Huang, M. Yue, M. Li, M. Wang, F. Kang, Preparation of Flexible Phenolic Resin-based Porous Carbon Fabrics by Electrospinning, Chem. Eng. J. 218 (2012) 232-237.

[46] S. Porada, L. Weinstein, R. Dash, A. Van Der Wal, M. Bryjak, Y. Gogotsi, P. Biesheuvel, Water desalination using capacitive deionization with microporous carbon electrodes, ACS Appl. Mater. Interfaces 4 (2012) 1194-1199.

[47] S. Porada, L. Borchardt, M. Oschatz, M. Bryjak, J. Atchison, K.J. Keesman, S. Kaskel, M. Biesheuvel, V. Presser, Direct Prediction of the Desalination Performance of Porous Carbon Electrodes for Capacitive Deionization, Energy Environ. Sci. 6 (2013) 3700-3712.

[48] E. Garcia-Quismondo, C. Santos, J. Lado, J. Palma, M.A. Anderson, Optimizing the Energy Efficiency of Capacitive Deionization Reactors Working under Real-World Conditions, Environ. Sci. Technol. 47 (2013) 11866-11872.

[49] Z.-H. Huang, M. Wang, L. Wang, F. Kang, Relation between the charge efficiency of activated carbon fiber and its desalination performance, Langmuir 28 (2012) 5079-5084. 
[50] S. Wang, D. Wang, L. Ji, Q. Gong, Y. Zhu, J. Liang, Equilibrium and kinetic studies on the removal of $\mathrm{NaCl}$ from aqueous solutions by electrosorption on carbon nanotube electrodes, Sep. Purif. Technol. 58 (2007) 12-16.

[51] X. Wang, M. Li, Y. Chen, R. Cheng, S. Huang, L. Pan, Z. Sun, Electrosorption of NaCl solutions with carbon nanotubes and nanofibers composite film electrodes, Electrochem. Solid-State Lett. 9 (2006) E23-E26.

[52] H. Li, L. Pan, Y. Zhang, L. Zou, C. Sun, Y. Zhan, Z. Sun, Kinetics and thermodynamics study for electrosorption of $\mathrm{NaCl}$ onto carbon nanotubes and carbon nanofibers electrodes, Chem. Phys. Lett. 485 (2010) 161-166.

[53] C. Tsouris, R. Mayes, J. Kiggans, K. Sharma, S. Yiacoumi, D. DePaoli, S. Dai, Mesoporous carbon for capacitive deionization of saline water, Environ. Sci. Technol. 45 (2011) 10243-10249.

[54] Y. Liang, Z. Li, R. Fu, D. Wu, Nanoporous carbons with a 3D nanonetwork-interconnected 2D ordered mesoporous structure for rapid mass transport, J. Mater. Chem. A 1 (2013) 3768-3773. 


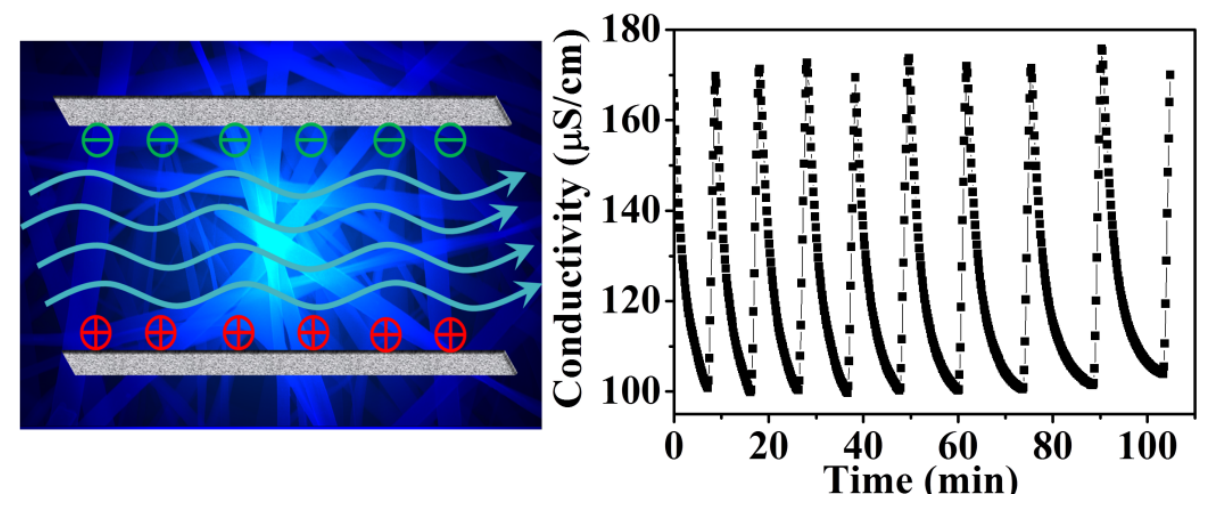

